DOI: 10.22616/REEP.2020.039

\title{
Nutrition Education on Graceful Aging among Staff in Senior Secondary Schools in Lagos State Nigeria
}

\author{
Ruth O. Oyegunwa ${ }^{1} \mathrm{PhD} ;$ Joy B. Osedume ${ }^{2}$ \\ Christiana T. Gbadebo ${ }^{3} \mathrm{PhD}$; Victoria T. Aladewolu ${ }^{4} \mathrm{PhD}$ \\ Federal College of Education (Technical) Akoka, Yaba, School of Vocational Education, \\ Department of Home Economics Education, Lagos State, Nigeria ${ }^{1,2,4}$ \\ University of Ilorin, Faculty of Agriculture, Department of Home Economics and Food Science, \\ Ilorin, Nigeria ${ }^{3}$ \\ toyinoyegunwa@yahoo.com ${ }^{1,2}$; gbadebo.ct@unilorin.edu.ng ${ }^{3}$; temiwolu@gmail.com ${ }^{4}$
}

\begin{abstract}
The study investigated Nutrition Education on Graceful Aging among Senior Secondary School Staff in Mushin Local Government Area of Lagos State, Nigeria. The aim of the study is to investigate nutrition education on graceful aging of senior secondary school staff in Mushin Local Government area of Lagos State, Nigeria. The study adopted a descriptive survey design. The population of this study is one hundred and ninety-one (191). Sample size for the study comprised one hundred (100) staff. The instrument used in carrying out this study is questionnaire titled - Nutrition Education on Graceful Aging. The study revealed that majority of respondents agreed to the statement that nutritional education can promote graceful aging, teaches that over nutrition causes problem such as obesity, similarly, majority of respondents also agreed that source of nutrition education and graceful aging are gotten from their academic background and also agreed that nutritional education and graceful aging campaign should be intensified through various media such as radio, television programme, and social media among others with. It is also revealed that majority of respondents agreed that skipping meals and eating more than adequate is against nutrition education and graceful aging and also responded that considering all the junks that can be on social media, is important to properly research all information pertaining to nutrition and graceful aging before utilizing it. It was revealed that there is a difference statistically in male teacher's educational background and that of their female counterparts as the hypothesis was rejected. Having analysed the survey data, it is possible to say nutrition education plays a pivotal role in graceful aging and that education attainment is also a key factor in enjoying graceful aging.
\end{abstract}

Keywords: nutrition education, graceful ageing, school staff, adult education.

\section{Introduction}

The nutrition education is the process of teaching the science of nutrition to an individual or group of persons. The nutrition education is any combination of educational strategies, accompanied by environmental supports, designed to facilitate voluntary adoption of food choices and other food- and nutrition-related behaviours conducive to health and well-being. According to J. McNulty (2013), nutrition education is delivered and involves activities at the individual, community, and policy levels. The nutrition education provided within family can be significantly affected by tradition, including the various elements of cultural heritage such as traditional food, traditional methods of its preparation, and finally eating habits. The impact of culture is the reason for the existence of separate ethnic cuisines, including national cuisine, regional cuisine, and even the family cuisine. The food culture is to a high extent determined by the natural resources of flora and fauna, climate and the presence of water reservoirs. The process of its formation is also influenced by religion and both historical and social changes. Other factors that have influence on the development of food culture are wars, business contacts or political relations with other nations (Jezewska-Zychowicz, 2018).

The art of nutrition education is the breaking down of a large body of knowledge into small, individual components that are represented a rate and level, at which they are able to absorb and use the information by the recipients. Effective nutrition education is making nutrition information available and usable in an everyday setting. Nutrition education is part of Applied Nutrition that focuses its resources toward learning, adaptation and acceptance of healthy eating habits, according to one's own food culture and scientific knowledge in nutrition, all with the ultimate aim of promoting health of the individual or community. It is very useful in health promotion and primary prevention to further the acquisition of healthy eating habits. It is also 
a useful strategy in the adoption of therapeutic dietary prescriptions and secondary prevention (McNulty, 2013). One of the most important factors determining human health and quality of life is proper nutritional habits, whereas unbalanced nutrition impacts the development of certain diseases, incidence of chronic noninfectious diseases (e.g. diabetes mellitus, cardiovascular diseases, etc.) as well as increases mortality. Nutrition is becoming a very important factor affecting all age groups. Assessing the pathogenesis of many diseases in every stage of life, balanced nutrition and proper habits have a favourable impact on human health (Cecchini et al., 2010). For a nation economic and sustainable development to be guarantee, its employable individuals must be healthy and one way of achieving healthy lifestyle is through nutrition education.

Nowadays people are living longer, healthier lives thanks to public health advances and medical research breakthroughs. Humanity is on the border with the "Longevity Revolution". More than one in five Americans is over the age of 65 and potentially more than one million are centenaries. By turning our attention to understanding aging and age- related diseases we can extend the healthy, active lives of older adults and limit the economic and personal burdens of an aging nation (Kaslec et al., 2005).

When people talk about getting older, it's not uncommon for them to use the term 'aging gracefully'. Aging gracefully is often used as a euphemism. People may use the phrase to mean, "Looking old, but embracing it" or "Showing signs of aging, but still powering forward with life." In this way, the term feels almost negative or backhanded - it's the phrase we use to describe someone who is not looking as good as they once did (The America Society..., 2013). Graceful Aging is America's leading video network for boomers and older adults. Discover great ways to a vibrant senior life and gain important caregiver advice on elder care. It is important to stay informed on assisted living (Graceful aging, 2019). Experts say the keys to successful aging include accepting changes and finding meaningful activities (Kam, 2019). Graceful aging is a topic of interest to many as it affects almost everyone during their lifetime. There are many suggestions on how to make old age beautiful and live a meaningful life (Morrison, 2010; Colino, 2015; Michaels, 2018; How to Live..., 2019; National Council..., 2019). Perhaps aging gracefully doesn't necessarily have to refer to age or appearance, but rather the attitude people have as they go through the various stages of life. For any nation or country to attain sustainable development its citizens must be aware of graceful aging and age gracefully, hence this study becomes important and relevant.

Home Economists learns and teaches which nutrients are necessary for human health and maintenance of life and which food includes such nutrients, as well as the knowledge, skills and techniques related to cooking that make it possible to enjoy eating foods without reducing the nutrient value, which in turn result to adequate and balance diet for individual. It is as a result of the foregoing views this study examined nutrition education on graceful aging among staff (teaching and non-teaching) in Senior Secondary Schools in Mushin Local Government area of Lagos State, Nigeria. Good nutrition is paramount in maintaining life and is an activity encouraged to be shared by everyone all around the world. However, while some people suffer from hunger, other people suffer from lifestyle-related illnesses due to ignorant of nutrition education. Food and nutrition education is given to people to improve people's dietary habits and educate them on the timing of food consumption, but in our society of Nigeria, it is not impossible that these services rendered in the advanced nations are not well given a priority by so called the home economists especially to the aging ones. It is as a result of this the urge emanated to investigate nutrition education on graceful aging among staff in senior secondary schools Mushin Local Government area of Lagos State, Nigeria.

The main purpose of the study is to investigate nutrition education on graceful aging among staff in senior secondary schools, Mushin Local Government area of Lagos State, Nigeria. Specifically, the main purposes are:

- to examine nutrition education on graceful aging among staff in senior secondary schools,

- to investigate if educational background affects nutritional practices and graceful aging among male and female staff in senior secondary school.

\section{Methodology}

\section{Research Design}

The study adopted a descriptive survey research design method, which include mean and t-test. The following research questions were raised to guide the conduct of the study:

- what is the effect of nutrition education on graceful aging among staff in senior secondary schools; 
- does educational background affect nutritional practices and graceful aging among male and female staff in senior secondary schools.

\section{Research Hypothesis}

There is no significant difference in nutrition education background among male and female staff in senior secondary schools.

\section{Population of the Study}

The population of this study comprised of all senior secondary schools' staff in seven senior secondary schools in Mushin Local Government, Lagos State, Nigeria. A total number of one hundred and ninetyone (191) staff from seven senior secondary schools in the area formed the population for this study. Staff of the senior secondary schools includes, teachers (teaching staff), cleaners, clerical officers on duty and security officers (non-teaching staff).

\section{Sample and Sampling Techniques}

A sample size of one hundred (100) staff was selected for the study, making a total of $52 \%$ of the population. Simple random sampling technique was used to select the sample.

\section{Instrument of Data Collection}

The instrument used in carrying out this study is a fifteen (15) items structured questionnaire titled Nutrition Education on Graceful Aging. The questionnaire consists of Section A and section B, section A is the personal characteristics of the respondents while Section B contains questions on nutrition education and graceful aging among staff in senior secondary school. The questionnaire was structured using Likert scale items Strongly Agreed $(\mathrm{SA})=4$, Agree $(A)=3$, Disagree $(\mathrm{D})=2$ and Strongly Disagree $(\mathrm{SD})=1$, respectively. The staff took part in the study voluntarily, and the questionnaire was anonymous so that the respondents could express their viewpoints unreservedly. The goal and methodology of the research were explained to the staff.

To research nutrition education of staff in senior secondary schools, a theoretical analysis of scientific literature was conducted first and accordingly and a modified Likert Scale questionnaire was created. The questions were about personal characteristics of respondents, nutrition education and educational background. The statistical data were processed using the SPSS (Statistical Package of Social Sciences, 20.0) programme.

\section{Results and Discussion}

More than half of the surveyed staff of Senior Secondary School are female with $57 \%$ while male is $43 \%$. Majority (34\%) of respondents are within the age of 30-35 years, $31 \%$ are 20 - 25years of age, while $22 \%$ are of the age 25 - 30 years and $13 \%$ are within the age of 30-35 years and above. Educational qualification of the respondents Senior School Certificate Exam (SSCE) is a certificate for individual who has passed through a 3years post primary school at the junior secondary school and 3 years in senior secondary. Nigeria Certificate in Education (NCE) is having completed a 3years programme in a college of education in the country while National Diploma (ND) is a diploma certificate from any reputable polytechnic in the country. Higher National Diploma (HND) is as the name implies in a reputable in a polytechnic with two years programme for each programme respectively. Bachelor in Education is a certificate obtained after completion of a four years programme in the university while Master in Education (M.Ed.) is obtained on completion of a post graduate programme in education for a period of eighteen (18) months. Finding from the research shows that majority which is $39 \%$ of the respondents has NCE/ ND certificate, while $27 \%$ has HND certificate, $17 \%$ has Bachelor in Education, $12 \%$ are with SSCE and only $3 \%$ has M.Ed. certificate. Among the selected respondents, $49 \%$-non- teaching and $51 \%$-teaching staff. Service years of respondents which depict that majority which is $60 \%$ within $6-10$ years, $28 \%$ has below 2-5 years while $12 \%$ has 11years and above. Having analysed the surveyed data, it is possible to state that most staff acquired their nutrition education from their academic background.

Finding shows in the Table 1 about nutrition education on graceful aging. It is revealed that majority of respondents agreed to the statement that nutritional education can promote graceful aging (mean is 3.57 ), 
teaches that over nutrition causes problem such as obesity, hence not aging gracefully (3.40). Nutrition education is a precursor graceful aging with a mean of 3.42 respectively.

Analyse of the research Question One: What is the effect of nutrition education on graceful aging?

Table 1

Distribution of respondents' answers to the first research question

\begin{tabular}{|c|c|c|c|c|c|c|}
\hline Questions & SA & $\mathbf{A}$ & D & SD & Mean & $\begin{array}{l}\text { Standard } \\
\text { Deviation }\end{array}$ \\
\hline Nutrition education can promote graceful aging & 59 & 40 & - & 1 & 3.57 & 0.56 \\
\hline $\begin{array}{l}\text { Nutrition education teaches that over nutrition causes } \\
\text { problem such as obesity hence not cause problem as such } \\
\text { obesity hence not aging gracefully. }\end{array}$ & 43 & 54 & 3 & - & 3.40 & 0.55 \\
\hline Nutrition education is a precursor graceful aging & 52 & 38 & 10 & - & 3.42 & 0.67 \\
\hline $\begin{array}{l}\text { My source of nutrition education and graceful aging are } \\
\text { gotten from my academic background. }\end{array}$ & 31 & 47 & 22 & - & 3.10 & 0.73 \\
\hline $\begin{array}{l}\text { Nutrition education and graceful aging campaign should be } \\
\text { intensified through various media such as radio, television } \\
\text { programme, and social media among others. }\end{array}$ & 66 & 34 & - & - & 3.66 & 0.48 \\
\hline $\begin{array}{l}\text { Skipping meals and eating more than adequate is against } \\
\text { nutrition education and graceful aging. }\end{array}$ & 37 & 46 & 5 & 12 & 3.08 & 0.95 \\
\hline $\begin{array}{l}\text { Considering all the junks that can be on social media, is } \\
\text { important to properly research all information pertaining to } \\
\text { nutrition and graceful aging before utilizing it. }\end{array}$ & 39 & 40 & 20 & 1 & 3.17 & 0.78 \\
\hline
\end{tabular}

Similarly, majority of respondents also agreed that source of nutrition education and graceful aging are gotten from their academic background with a mean opinion of 3.10 and also agreed that nutritional education and graceful aging campaign should be intensified through various media such as radio, television programme, and social media among others with a mean of 3.66. It is also revealed that majority of respondents agreed that skipping meals and eating more than adequate is against nutrition education and graceful aging and also responded that considering all the junks that can be on social media, is important to properly research all information pertaining to nutrition and graceful aging before utilizing it with a mean of 3.08 and 3.17 respectively.

Analyse of the research Question Two: Does educational background affect nutritional practice and graceful aging?

Finding shows in the Table 2 about educational background on nutritional practice and graceful aging. It is revealed from the study that majority of respondents agreed emphatically that the level of education can positively affect nutritional practice hence graceful aging and also agreed that their nutrition education and graceful aging, information is supported by their educational background and that their educational background help them to have positive awareness as regards nutrition education and graceful aging with a mean of $3.11 ; 3.30$ and 3.54 respectively.

Table 2

Distribution of respondents' answers to the first research question

\begin{tabular}{lcccccc}
\hline \multicolumn{1}{c}{ Questions } & SA & A & D & SD & Mean & $\begin{array}{c}\text { Standard } \\
\text { Deviation }\end{array}$ \\
\hline $\begin{array}{l}\text { Level of education can positively affect nutritional practice } \\
\text { hence graceful aging }\end{array}$ & 43 & 38 & 6 & 12 & 3.11 & 1.00 \\
$\begin{array}{l}\text { My nutrition education and graceful aging information is } \\
\text { supported by my educational background }\end{array}$ & 36 & 58 & 6 & 11 & 3.30 & 0.58 \\
$\begin{array}{l}\text { My educational background helps me to have positive } \\
\text { awareness as regards nutrition education and graceful aging }\end{array}$ & 57 & 40 & 3 & - & 3.54 & 0.56 \\
\hline
\end{tabular}


Hypothesis testing descriptive statistics are shown in Table 3.

Table 3

Descriptive statistics

\begin{tabular}{cccc}
\hline Gender & N & Mean & Standard Deviation \\
\hline Male & 43 & 3.442 & 0.983 \\
Female & 57 & 3.614 & 1.130 \\
\hline
\end{tabular}

The Table 4 shows the t-test statistical difference in nutrition education background of male and female on graceful aging among senior secondary school staff. It was revealed that there is a difference statistically in male staff nutrition education background and that of their female counterparts as the hypothesis is rejected $\mathrm{t}(99)=-27.596, \mathrm{p}=0.00$.

Table 4

\section{T-test statistics}

\begin{tabular}{cccccc}
\hline & Mean & $\begin{array}{c}\text { Standard } \\
\text { Deviation }\end{array}$ & t & Df & Sig. (2-tailed) \\
\hline Gender_Educational background & -2.000 & 0.724 & -27.596 & 99 & 0.000 \\
\hline
\end{tabular}

Since $\mathrm{p}<0.05$ level of significance, we hereby reject the hypothesis and conclude that there is a significance difference in male nutrition education background and that of their female counterparts in their nutritional education on gracefully aging among senior secondary school staff.

From research question one, it was revealed that majority of respondents agreed to the statement that nutrition education can promote graceful aging, teaches that over nutrition causes problem such as obesity, hence not aging gracefully. This is in direct agreement with (Chang, Roberts, 2008) that asserted that, Nutrition education has the potential to encourage the older adults to consume a variety of foods and lead a healthy life. I. Kepaliene and D. Gudaviciute asserted that in modern society healthy nutrition is a particularly topical issue as it is one of the key elements of a healthy lifestyle which determines a person's well-being. According to their research results two important factors determining unhealthy nutrition are: lack of time and lack of will (Kepaliene, Gudaviciute, 2019).

Findings from research question two showed that majority of respondents agreed emphatically that their level of education can positively affect nutrition practice hence graceful aging and also agreed that their nutrition education and graceful aging, information is supported by their educational background and that their educational background help them to have positive awareness as regards nutrition education and graceful aging. N.C. Van Nie-Visser directly supported the claim when opined that, among risk factors associated with malnutrition, level of education which plays a pivotal role in nutritional status as it can affect the ability to make reliable and aware of food choices (Van Nie-Visser et al., 2014). Other scientists claimed that elderly education level had a significant effect on their nutritional status (Abdelwahed, Algameel, Tayel, 2018). In the research (Donini et al., 2013; Leslie, Hankey, 2015) it is mentioned that the majority of elder patients presented with nutritional inadequacies and malnutrition were of lower educational levels. This might be justified that lower level of education and limited literacy hindering elderly people from access to proper nutrition related information.

Findings from the hypothesis concluded that there is a significance difference in male staff nutrition education background and that of their female counterparts on graceful aging.

\section{Conclusions}

- The place of studies is closely related to the study, the place of work often affects nutrition education. During the study period, staffs were aware that nutrition education can promote graceful aging and that academic background had been a good source of nutrition education to the staff. Is also very important to note that, it was revealed statistically that there is a difference in male teacher's educational background and that of their female counterparts as the hypothesis was rejected.

- For a nation economic and sustainable development to be guarantee, its employable individuals must be healthy and one way of achieving healthy lifestyle is through Nutrition Education. 
- Nutrition education plays a pivotal role in graceful aging and that education background is also a key factor in enjoying graceful aging.

- Graceful aging involved staying informed on assisted living, accepting changes, finding meaningful activities and as aging is a topic of interest to many as it affects almost everyone during their lifetime.

\section{Bibliography}

1. Abdelwahed A.Y., Algameel M.M.M., Tayel D.I. (2018). Effect of a Nutritional Education Program on Nutritional Status of Elderly in Rural Areas of Damanhur City, Egypt. International Journal of Nursing Science, 8(5), 83-92. Retrieved from http://article.sapub.org/10.5923.j.nursing.20180805.02.html

2. Cecchini M., Sassi F., Lauer J.A., Lee Y.Y., Guajardo-Barron V., Chisholm D. (2010). Tackling of unhealthy Diets, Physical Inactivity and Obesity: Health Effects and Cost- Effectiveness. Lancet, 376, 1775-1784. doi: 10.1016/S0140-6736(10)61514-0

3. Chang C.C., Roberts B.L. (2008). Feeding difficulty in older adults with Dementia. Journal of Clinical Nursing, 17(17), 2266-2274. doi: 10.1111/j.1365-2702.2007.02275.x

4. Colino S. (2015). The Modern Guide to Aging Gracefully. Retrieved from https://www.realsimple.com/beauty-fashion/makeup/aging-gracefully?slide=5217\#5217

5. Donini L.M., Scardella P., Piombo L., Neri B., Asprino R., Proietti A.R., Carcaterra S., Cava E., Cataldi S. Cucinotta D., Di Bella G., Barbagallo M., Morrone A. (2013). Malnutrition in elderly: Social and economics determinants. Journal of Nutrition, Health and Aging, 17(1), 9-15. doi: 10.1007/s12603-012-0374-8

6. Graceful aging. (2019). Retrieved from http://www.gracefulaging.com

7. How to Live Your Life as You Age. (2019). Retrieved from https://www.healthline.com/health/aging-gracefully\#tips

8. Jezewska-Zychowicz M. (2018). Cooking Methods, Social Relations and Situations Related to Food as a part of Nutrition Education within Family. In V. Dislere (Ed.), The Proceedings of the International Scientific Conference Rural Environment Education Personality (REEP), 11. Jelgava: Latvia University of Life Sciences and Technologies, 261-268. doi: 10.22616/REEP.2018.032

9. Kam K. (2019). The Art of Aging Gracefully. Retrieved from https://www.webmd.com/healthyaging/features/the-art-of-aging-gracefully\#1

10. Kaslec A., Arumi A.M., Immerwahr J., Barry L. (2005). The Science of Aging Gracefully. New York: Public Agenda. Retrieved from https://www.afar.org/docs/migrated/AFARScienceofAgingGracefully.pdf

11. Kepaliene I., Gudaviciute D. (2019). Research of Nutritional Habits of Prospective Teachers. In V. Dislere (Ed.), The Proceedings of the International Scientific Conference Rural Environment Education Personality (REEP), 12. Jelgava: Latvia University of Life Sciences and Technologies, 225-230. doi: 10.22616/REEP.2019.029

12. Leslie W., Hankey C. (2015). Aging, Nutritional Status and Health. Healthcare 3(3),648-658. doi: $10.3390 /$ healthcare 3030648

13. McNulty J. (2013). Challenges and Issues in Nutrition Education. Rome: Nutrition Education and Consumer Awareness Group, Food and Agriculture Organization of the United Nations. Retrieved from http://www.fao.org/publications/card/en/c/4e5e1987-7c4b-50a4-b8e7-8cf1ca17ebeb

14. Michaels J. (2018). Your Self- Care Guide to Aging Gracefully. Retrieved from https://www.success.com/your-self-care-guide-to-aging-gracefully/

15. Morrison A.M. (2010). Aging Gracefully, the French Way. Retrieved from https://www.nytimes.com/2010/07/15/fashion/15French.html

16. National Council for Aging Care. (2019). 10 Tips to Age Beautifully. Retrieved from https://www.aging.com/ten-tips-to-age-beautifully/

17. The America Society for Aesthetic Plastic Surgery. (2013). What does aging gracefully mean? Retrieved from https://www.surgery.org/consumers/plastic-surgery-news-briefs/aging-gracefullymean-1051522.

18. Van Nie-Visser N.C., Meijers J., Schols J., Lohrmann C., Bartholomeyczik S., Spreeuwenberg M., Halfens R. (2014). Which characteristics of nursing home residents influence differences in malnutrition prevalence? An International comparison of the Netherlands, Germany and Austria. British Journal of Nutrition, 111(6), 1129-1136. doi: 10.1017/S0007114513003541 